\title{
NFKB activation in cutaneous lesions of leprosy is associated with development of multibacillary infection
}

This article was published in the following Dove Press journal:

Journal of Inflammation Research

25 August 2014

Number of times this article has been viewed

\author{
Carlos G Wambier' \\ Leandra Naira Z Ramalho \\ Marco Andrey C Frade' \\ Norma T Foss' \\ 'Division of Dermatology, \\ Department of Internal Medicine, \\ ${ }^{2}$ Department of Pathology, Ribeirão \\ Preto School of Medicine, University \\ of São Paulo, Ribeirão Preto, São \\ Paulo, Brazil
}

Background: Nuclear factor kappa B (NFאB) transcription factors play a central role in controlling the expression of genes involved in inflammatory reactions, proliferation, and survival of human cells. However, the in situ evaluation of NFKB activity in leprosy has not been completed previously. The aim of this study was to determine whether NF $\mathrm{kB}$ activity correlates with susceptibility or resistance to Mycobacterium leprae infection in biopsies from skin lesions of 38 patients with the clinical and laboratory diagnosis of leprosy.

Methods: The NFKB activation profile was evaluated in biopsies from skin lesions of 38 patients with the clinical and laboratory diagnosis of leprosy. NFKB activation was evaluated and quantified by Southwestern histochemistry, and its activation index (range, 0-4) was calculated according to the percentage of nuclear positivity by the histochemistry. Activation index $>1$ was considered representative of activation of NFKB.

Results: Fifteen patients (39.5\%) demonstrated activated NFKB. Multibacillary leprosy was associated with activated NFKB $(54.5 \%, P=0.028)$. Borderline leprosy was most strongly associated with NFKB activation ( $80 \%$ ), with an odds ratio of 32.7 ( $P=0.016)$. These clinical forms are characterized by increased susceptibility to $M$. leprae and by immunological instability. Activation of NFKB was absent in the granulomas in tuberculoid leprosy, which represents an effective inflammatory reaction pattern against $M$. leprae.

Conclusion: These results indicate that NFKB activation could favor susceptibility and immunological instability to $M$. leprae infection, potentially by the stimulation of phagocytosis and the regulation of apoptotic mechanisms of infected cells, leading to the proliferation of this intracellular bacillus. Further studies are needed to evaluate if inhibition of NFKB activation in multibacillary leprosy could favor resistance and an effective granulomatous immune response.

Keywords: transcription factors, nuclear factor kappa B, immunomodulation, Mycobacterium leprae, leprosy resistance, leprosy susceptibility

\section{Introduction}

Leprosy is a chronic mycobacteriosis caused by Mycobacterium leprae that may produce a limited or disseminated infection in skin and peripheral nerves, leading to a spectrum of clinical manifestations based upon the level of cell mediated immunity (CMI) against the bacilli. At one end of the spectrum is tuberculoid leprosy (TT), characterized by restricted growth of the pathogen, and high CMI. At the opposite end of the spectrum is lepromatous leprosy (LL), characterized by widespread dissemination of bacilli, strikingly absent CMI, and a predominant humoral immune response against M. leprae. Between these two polar forms, there is the borderline group, which can be divided into three subgroups according to the CMI response: borderline tuberculoid (BT), borderline (BB), and borderline lepromatous (BL). ${ }^{1,2}$ 
The immunological aspects of leprosy have been extensively investigated, but the factors that facilitate or impair CMI in the polar manifestations of the disease are still not completely understood. It is known that the family of transcription factors named nuclear factor kappa B (NFкB) control the global inflammatory response by playing a central role in modulation of inflammatory reactivity. In resting cells, NFKB subunits are inactivated in the cytosol. ${ }^{3}$ Upon cytokine signaling, tumor necrosis factor alpha (TNF $\alpha$ ), or environmental stress, $\mathrm{NF \kappa B}$ activation is triggered to modulate inflammatory reactivity. ${ }^{4} \mathrm{NF} \kappa \mathrm{B}$ also acts as an important survival factor for human cells, by preventing apoptosis induced by TNF $\alpha .{ }^{5}$ This anti-apoptotic effect is mediated through the transcriptional up-regulation of NFKB-dependent anti-apoptotic proteins, such as TNF $\alpha$ receptor-associated factor 1 and factor 2 (TRAF-1 and TRAF-2) and the cellular inhibitor of apoptosis protein 1., Although M. leprae may induce apoptosis of Schwann cells via Toll-like receptor $2,{ }^{7}$ the contact of viable $M$. leprae in Schwann cells has also been shown to cause survival of these cells, instead of apoptosis, ${ }^{8}$ which could be associated with NFkB-dependent anti-apoptotic mechanisms.

Peripheral blood mononuclear cells (PBMC) from multibacillary leprosy (MB) patients and healthy blood donors exposed to inactivated $M$. leprae induced nuclear translocation of NFKB (p65/p50 and p50/p50 dimers) in both groups. Such activation was considered essential to the production of TNF $\alpha$ by in vitro culture of PBMC from both patients and healthy controls. ${ }^{9}$ In vitro cultures of adherent PBMC from healthy donors showed lower levels of activation of NFKB (p65) when exposed to M. leprae than when exposed to bacillus Calmette-Guérin, indicating a possible NF $\kappa \mathrm{B}$ signaling deficit in response to M. leprae. ${ }^{10}$

In situ studies of $\mathrm{NF \kappa B}$ activation could elucidate its role in the pathophysiology of the cutaneous manifestations of leprosy. It could be hypothesized that the cutaneous manifestations at the opposite ends of the spectrum of leprosy could be related to the activity of NFKB. For example, during the development of TT lesions, NFKB signaling induced by TNF $\alpha$ could be one of the factors that favor the effectiveness of the inflammatory reaction and complete bacilli destruction by CMI. On the other hand, during the development of LL lesions, the anti-apoptotic activity of NFKB could allow intracellular parasitic activity and multiplication of the bacilli. The aim of this study was to determine whether $\mathrm{NF \kappa B}$ activity correlates with susceptibility or resistance to $M$. leprae infection in biopsies from skin lesions of
38 patients with the clinical and laboratory diagnosis of leprosy.

\section{Material and methods}

This study used previously archived formalin-fixed and paraffin-embedded skin biopsy specimens, and data from the medical records of leprosy patients followed in the Leprosy Outpatient Clinic of the National Reference Centre for Sanitary Dermatology with Emphasis on Leprosy of the Hospital of Clinics at the Ribeirão Preto School of Medicine at the University of São Paulo. During routine follow-up at the outpatient clinic, all patients are classified according to the Ridley-Jopling spectrum (TT, BT, BB, BL, and LL) and by the World Health Organization (WHO) operational classification (MB, more than five skin lesions; and paucibacillary leprosy (PB), up to five skin lesions).

The ethics committee at the Hospital of Clinics, Ribeirão Preto Medical School, University of São Paulo, approved this study under consent number 2763/2011. Patients were not required to give written consent as data was analyzed anonymously; medical record information, all samples (including biopsies), and test results were previously gathered and were not obtained specifically for this study.

The patients included in the study had a clinical diagnosis of leprosy and had a skin biopsy performed at time of diagnosis, with adequate leprosy classification by RidleyJopling spectrum (TT, BT, BB, BL, and LL). Epidemiological and clinical data were obtained from the patients' medical records, including classification by Ridley-Jopling criteria, WHO operational classification, comorbidities, and the use of alcohol, tobacco, and medications. The selection criteria were based on all patients whose first biopsy by the Leprosy Outpatient Clinic was performed between 2006 and 2010.

Patients were excluded from the study if medical records indicated: the use of non-steroidal anti-inflammatory drugs or corticosteroids 14 days before the date of the biopsy; leprosy reactions in the disease course; inflammatory diseases; drug eruptions in the past 3 months; higher doses than the standard multidrug therapy for treatment of leprosy or previous complete treatment; severe comorbidity or life threatening event in the past 6 months; pregnant or breastfeeding patients; and chronic disease that might interfere with inflammatory mechanisms such as diabetes mellitus, lymphedema, chronic renal disease, chronic heart failure, smoking, alcoholism, and malnutrition. A total of 24 initially selected patients were excluded from the study based on one or more of these exclusion criteria, (nine BB, six BL, five LL, two BT, and two TT). Clinical forms outside the typical 
leprosy spectrum such as indeterminate leprosy and pure neural leprosy were also not included in this study.

Skin biopsies were performed with a disposable skin biopsy punch (diameter $4 \mathrm{~mm}$ ) after local anesthesia ( $2 \%$ lidocaine plus epinephrine tartrate 1:200,000 IU). All specimens were formalin-fixed and paraffin-embedded. Histopathological examination with standard hematoxylineosin staining, and the Fite-Faraco staining technique was used for the detection of $M$. leprae bacilli.

Biopsies underwent Southwestern histochemistry for in situ detection and distribution of the DNA-binding activity of NFKB. The non-radioactive in situ detection of activated $\mathrm{NF \kappa B}$ in paraffin-embedded skin tissue preparations was performed as previously described, ${ }^{11}$ using digoxigenin labeling and detection kits (Roche Applied Science, Indianapolis, IN, USA). Synthetic sense DNAs (Imprint Genetics Corporation, Hialeah, FL, USA), which contained NFKB sequences, were used as the probe. After annealing with the complementary sequence, the DNA probe 5'-AGTTGAGGGGACTTTCCCAGGC-3' was labeled with digoxigenin. The sections were then incubated with the labeled probes for 12 hours at $37^{\circ} \mathrm{C}$. They were then incubated with an anti-digoxigenin antibody conjugated with alkaline phosphatase and detected using a nitro-blue tetrazolium and 5-bromo-4-chloro-3-indolylphosphate solution. 5'-AGTTGAGGCTCCTTTCCCAGGC-3' (mutant form of the probe) was used as a negative control. Only cells exhibiting homogenous distinct purple nuclear staining were considered positive. The number of NFKB-positive cell nuclei was estimated in percentage in ten randomly chosen high-power fields $(400 \times)$ in each sample, from which mean values were calculated. NFKB activation index (range, 0-4) was set to quantify the final percentage of positivity, ie, " 0 " when $0 \%$ of nuclei were positive, " 1 " when $1 \%-10 \%$ of nuclei were positive, "2" when $11 \%-25 \%$ of nuclei were positive, "3" when $26 \%-50 \%$ of nuclei were positive, and " 4 " when $>50 \%$ of nuclei were positive, as shown in Figure 1 . The criteria for activated NFKB was the presence of an activation index $>1$ (ie, activation indices of 2, 3, and 4). Hematoxylin-eosin staining is not performed with this technique; therefore, violet staining indicates only nuclei with activated NFKB. The pathologist who scored NFKB indexes was blinded regarding the previous classification of leprosy of the subjects.

Among the 38 selected patients, the mean age was $47.4 \pm 21.2$ years, and $22(57.9 \%)$ were male. Twenty-two patients $(57.9 \%)$ were classified as MB: five had BB (13.1\%),

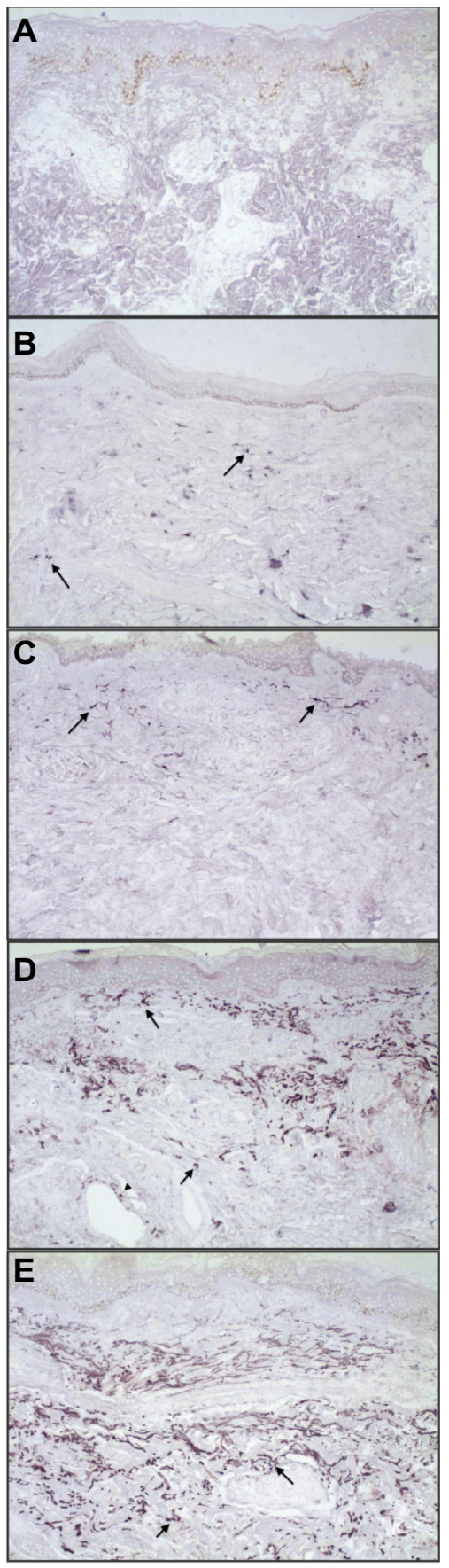

Figure I Representative photomicrographs of skin biopsies submitted for Southwestern histochemistry for detection of activated NFKB (original magnification 200x).

Notes: Arrows demonstrate purple nuclear staining. Detection was quantified by an NFKB activation index, which values ranged from zero to four. (A) NFKB activation index of 0 : no nuclear staining (negative control); (B) NFKB activation index of I: up to $10 \%$ nuclear staining in sparse lymphocytes from a tuberculoid lesion; (C) NFKB activation index of 2: $11 \%-25 \%$ nuclear staining in cells from a superficial lymphohistiocytic infiltrate and fibroblasts (arrows) from a borderline tuberculoid lesion; (D) NFKB activation index of 3: $26 \%-50 \%$ nuclear staining in cells from a perivascular and perineural inflammatory infiltrate, involving the superficial and mid dermis. There was staining of histiocytes, lymphocytes, fibroblasts, and vascular endothelium (arrow tip) from a lepromatous lesion; (E) NFKB activation index of $4:>50 \%$ nuclear staining in cells from a dense perineural and perivascular inflammatory infiltrate. There was staining of fibroblasts, histiocytes, and lymphocytes from a borderline lesion.

Abbreviation: NFאB, nuclear factor kappa B. 
eight had BL (21.1\%), and nine had LL (23.7\%). Sixteen patients (42.1\%) were classified as PB: seven had TT (18.4\%), and nine had BT (23.7\%).

Fisher's exact test was used to evaluate the significance of the association between categorical variables. Logistic regression was used to determine the strength of association (odds ratio $[\mathrm{OR}]$ ) between $\mathrm{NF} \kappa \mathrm{B}$ activation and the clinical classification of leprosy, adjusted for age and sex. $P$-values $<0.05$ were considered statistically significant. Statistical analysis was performed using software STATA ${ }^{\mathrm{TM}} 12$ (StataCorp LP College Station, TX, USA).

\section{Results}

The median NFאB activation index was 1 (range, 0-4). $\mathrm{NF} \kappa \mathrm{B}$ was activated (activation index $>1$ ) in 15 skin lesions (39.5\%), with an activation index of 4,3 and 2 in one, five, and nine patients, respectively. In the remaining 23 lesions $(60.5 \%)$ NFKB was not activated, with an activation index of 1 and 0 in 22 and seven patients, respectively. The presence of NFKB activation in the skin lesions varied strikingly according to the clinical form of leprosy. TT lesions had $0 \%$ with NF $\kappa \mathrm{B}$ activation, BT had $33 \%$ with $\mathrm{NF} \kappa \mathrm{B}$ activation, $\mathrm{BB}$ had $80 \%$ with $\mathrm{NF} \kappa \mathrm{B}$ activation, $\mathrm{BL}$ had $50 \%$ with NFKB activation, and LL had $44 \%$ with $\mathrm{NF} \kappa \mathrm{B}$ activation.
$\mathrm{NF} \kappa \mathrm{B}$ activation indices were higher in $\mathrm{MB}$ patients (median $=2$; range, $0-4$ ), than in $\mathrm{PB}$ patients (median $=1$; range, $0-2$ ), with a higher frequency of activated $\mathrm{NF} \kappa \mathrm{B}$ in MB patients (54.5\%) than in PB patients $(18.8 \% ; P=0.028)$, as shown in Table 1. All three PB patients with activated NF $\kappa$ B had the clinical form of BT. TT was associated with absence of activation of NFKB $(P=0.019)$, with an activation index of 1 in six patients and 0 in one patient. BB leprosy had the highest frequency of activated NF $\kappa \mathrm{B}(80 \%)$, with an OR of 32.7 ( $P=0.016$; Table 2 ), and an activation index of 4 in one patient (the highest activation index of this study), 3 in one patient, 2 in two patients, and 1 in one patient (Table 3 ).

\section{Discussion}

Based on the data of this study, patients with the most effective immune reactivity against $M$. leprae bacilli (TT) had

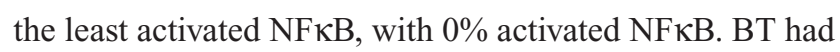
a low frequency of NFKB activation at $33.3 \%$. These findings may depict the low inflammatory profile in the chronic and stable granulomatous reaction, which is associated with previous destruction of bacilli and efficient deprivation of mycobacterial antigens. On the other hand, the clinical forms with immunological instability had a higher frequency of

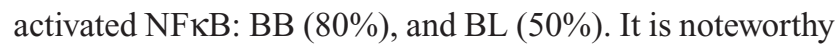
that within $\mathrm{MB}$, the forms that usually present with upgrading

Table I Data from 38 leprosy patients evaluated for activation of NFKB

\begin{tabular}{|c|c|c|c|c|}
\hline & n (\%) & $\begin{array}{l}\text { NFKB index } \\
\text { median (range) }\end{array}$ & $\begin{array}{l}\text { Activated } \\
\text { NFKB n (\%) }\end{array}$ & $\begin{array}{l}\text { Fisher's exact } \\
P \text {-value }\end{array}$ \\
\hline \multicolumn{5}{|l|}{ Age group } \\
\hline$<18$ years & $4(10.5)$ & I (0-2) & I (25.0) & 0.480 \\
\hline $18-60$ years & $22(57.9)$ & I (0-3) & $6(27.3)$ & $0.07 \mid$ \\
\hline$>60$ years & $12(31.6)$ & $2(0-4)$ & $8(66.7)$ & $0.025^{*}$ \\
\hline \multicolumn{5}{|l|}{ Sex } \\
\hline Male & $22(57.9)$ & $1.5(0-3)$ & II (50) & 0.11 \\
\hline Female & $16(42.1)$ & I (0-4) & $4(25)$ & \\
\hline \multicolumn{5}{|l|}{ Leprosy classification } \\
\hline Tuberculoid & $7(18.4)$ & $I(0-I)$ & $0(0.0)$ & $0.019 *$ \\
\hline Borderline tuberculoid & $9(23.7)$ & I (0-2) & $3(33.3)$ & 0.490 \\
\hline Borderline & $5(13.2)$ & $2(1-4)$ & $4(80.0)$ & 0.069 \\
\hline Borderline lepromatous & $8(2 I . I)$ & $\mathrm{I} .5(\mathrm{I}-3)$ & $4(50.0)$ & 0.385 \\
\hline Lepromatous & $9(23.7)$ & I $(0-3)$ & $4(44.4)$ & 0.510 \\
\hline \multicolumn{5}{|l|}{ WHO classification } \\
\hline Multibacillary & $22(57.9)$ & $2(0-4)$ & $12(54.5)$ & $0.028^{*}$ \\
\hline Paucibacillary & $16(42.1)$ & I (0-2) & $3(18.8)$ & \\
\hline \multicolumn{5}{|c|}{ Biopsy acid-fast bacilli (Fite-Faraco stain) } \\
\hline Present & $29(76.3)$ & $\mathrm{I}(0-4)$ & $13(44.8)$ & 0.208 \\
\hline Absent & $9(23.7)$ & I (0-2) & $2(22.2)$ & \\
\hline Total & $38(100.0)$ & $\mathrm{I}(0-4)$ & $15(39.5)$ & \\
\hline
\end{tabular}

Note: $* p<0.05$.

Abbreviations: $n$, number of patients; NFאB, nuclear factor kappa B; WHO, World Health Organization. 
Table 2 Logistic regression analysis of activated NFKB according to leprosy classification, adjusted by age group and sex

\begin{tabular}{|c|c|c|c|c|}
\hline & $\begin{array}{l}\text { Activated } \\
\text { NFKB } \\
\text { n (\%) } \\
\end{array}$ & $\begin{array}{l}\text { Odds } \\
\text { ratio }\end{array}$ & $95 \% \mathrm{Cl}$ & $P$-value \\
\hline \multicolumn{5}{|l|}{ Age group } \\
\hline$<18$ years & I $(25.0)$ & I & - & - \\
\hline $18-60$ years & $6(27.3)$ & 0.12 & $0.01-3.06$ & 0.205 \\
\hline$>60$ years & $8(66.7)$ & 1.20 & $0.06-25.34$ & 0.905 \\
\hline \multicolumn{5}{|l|}{ Sex } \\
\hline Male & II (50) & 4.53 & $0.64-32.03$ & 0.129 \\
\hline Female & $4(25)$ & I & - & - \\
\hline \multicolumn{5}{|c|}{ Leprosy classification } \\
\hline $\begin{array}{l}\text { Tuberculoid } \\
\text { or borderline } \\
\text { tuberculoid }\end{array}$ & $3(33.3)$ & I & - & - \\
\hline Borderline & $4(80.0)$ & 32.70 & $1.92-557.49$ & $0.016 *$ \\
\hline $\begin{array}{l}\text { Borderline } \\
\text { lepromatous }\end{array}$ & $4(50.0)$ & 4.86 & $0.47-50.21$ & 0.185 \\
\hline Lepromatous & $4(44.4)$ & 1.77 & $0.20-15.83$ & 0.608 \\
\hline
\end{tabular}

Note: $* P<0.05$.

Abbreviations: $\mathrm{Cl}$, confidence interval; $\mathrm{NF \kappa B}$, nuclear factor kappa $\mathrm{B} ; \mathrm{n}$, number of patients.

or downgrading leprosy reactions (BB and BL) had more cells with NFKB activation than LL (44.4\%). Likewise, within PB the form which is more unstable and prone to leprosy reactions presented with increased NFKB activation BT (33.3\%), whereas TT, which is the most stable form presented with null activation $(0 \%)$.

MB demonstrated a higher frequency of activated NF $\kappa \mathrm{B}$ than $\mathrm{PB}(P=0.028)$, suggesting the possible role of bacillary antigens in modulatory processes, which may be activated through Toll-like receptors, cytokine modulation, and/or intracellular mycobacterial products. $\mathrm{NF} \kappa \mathrm{B}$ activation also regulates neural physiology by modulating synaptic plasticity and by regulating the growth of dendrites, ${ }^{12}$ suggesting that MB patients may have a higher activity of reparatory or adaptive mechanisms to the damage caused by the inflammatory response to, or intracellular activity of $M$. leprae bacilli.

TNF $\alpha$ may also trigger up-regulation of NFKBdependent anti-apoptotic proteins. ${ }^{5}$ Activated NFKB may inhibit apoptosis pathways and stimulate cell proliferation, allowing sufficient cell survival to host parasitic activity of these slowly duplicating mycobacteria. NFKB activation and its associated transcription modulation might be one of various bacillary adaptive mechanisms to allow chronic infection, which may in turn result in less effective host immunity. For example, if the inflammatory status mediated by $\mathrm{NF} \kappa \mathrm{B}$ in MB leprosy is not efficient enough to destroy $M$. leprae, this could even stimulate phagocytosis and consequent intracellular infection, similar to what has been reported with Trypanosoma cruzi, ${ }^{13}$ where microorganism invasion and survival is favored by $\mathrm{NF} \kappa \mathrm{B}$ activation induced by $\mathrm{TNF} \alpha$. Apoptosis has been shown to be more frequent in $\mathrm{PB}$ than in $\mathrm{MB}$, suggesting a possible mechanism for containing bacillary multiplication. ${ }^{14,15}$

Although age $>60$ years was associated with NFKB activation (66.7\%, $P=0.025$; Table 1$)$, it was not an independent risk factor by logistic regression analysis $(\mathrm{OR}=1.2, P=0.905$; Table 2). Seventy-five percent of these older patients presented with MB leprosy, and also the majority of LL patients $(55.6 \%)$ were aged $>60$ years.

This study reviewed patients treated at a large leprosy referral center between the years 2006-2010 and followed strict exclusion criteria, so was therefore limited by a small sample size. However, we feel that these initial findings are significant, and important in gaining a better understanding of the varied immunologic responses in leprosy patients, and

Table 3 Distribution of NFKB activation indexes by leprosy classification and WHO classification

\begin{tabular}{|c|c|c|c|c|c|c|}
\hline \multirow[t]{2}{*}{ Leprosy classification } & \multicolumn{6}{|c|}{ NFKB activation indexes } \\
\hline & $\begin{array}{l}0 \\
\text { n (\%) }\end{array}$ & $\begin{array}{l}\text { I } \\
\text { n (\%) }\end{array}$ & $\begin{array}{l}2 \\
\text { n (\%) }\end{array}$ & $\begin{array}{l}3 \\
\text { n (\%) }\end{array}$ & $\begin{array}{l}4 \\
\text { n (\%) }\end{array}$ & $\begin{array}{l}\text { Activated } \\
\text { NFKB (>I) } \\
\text { n (\%) }\end{array}$ \\
\hline Tuberculoid $(n=7)$ & I (I4) & $6(86)$ & $0(0)$ & $0(0)$ & $0(0)$ & $0(0)$ \\
\hline Borderline tuberculoid $(n=9)$ & $4(44)$ & $2(22)$ & $3(33)$ & $0(0)$ & $0(0)$ & $3(33)$ \\
\hline Borderline $(n=5)$ & $0(0)$ & I (20) & $2(40)$ & I (20) & I (20) & $4(80)$ \\
\hline Borderline lepromatous $(n=8)$ & $0(0)$ & $4(50)$ & $3(38)$ & I (I3) & $0(0)$ & $4(50)$ \\
\hline Lepromatous ( $n=9)$ & $\mathrm{I}(\mathrm{II})$ & $4(44)$ & $\mathrm{I}(\mathrm{II})$ & $3(33)$ & $0(0)$ & $4(44)$ \\
\hline \multicolumn{7}{|l|}{ WHO classification } \\
\hline Paucibacillary $(n=16)$ & $5(3 I)$ & $8(50)$ & $3(19)$ & $0(0)$ & $0(0)$ & $3(19)$ \\
\hline Multibacillary $(\mathrm{n}=22)$ & I (5) & $9(4 I)$ & $6(27)$ & $5(23)$ & I (5) & $12(55)$ \\
\hline
\end{tabular}

Abbreviations: NFKB, nuclear factor kappa B; n, number of patients; WHO, World Health Organization. 
we hope that this research will stimulate similar studies with a larger sample size.

\section{Conclusion}

Our study suggests that activation of NF $\kappa \mathrm{B}$ is associated with increased susceptibility to $M$. leprae infection, as well as immunological instability. The results show increased NFкB activation in skin lesions of $\mathrm{MB}$ and $\mathrm{BB}$ patients, in contrast to scarce activation in skin lesions of $\mathrm{PB}$, with no activation in TT. Future studies are needed to analyze the role of NFאB in acute leprosy inflammatory reactions, its activation after multidrug therapy, and the possibility of NFאB inhibition to favor resistance and an effective granulomatous immune response against the bacilli.

\section{Acknowledgments}

The authors thank Mark A Cappel, MD, Department of Dermatology, Mayo Clinic, Jacksonville, Florida, for his help with the English language revision. The authors are also grateful to Ms Auristella de Melo Martins for her excellent laboratory assistance. The authors also wish to thank FAEPA (Fundacao de Apoio ao Ensino, Pesquisa e Assistencia, Hospital of Clinics, Ribeirão Preto School of Medicine, University of São Paulo) for funding and support.

\section{Disclosure}

The authors report no conflicts of interest related to this work.

\section{References}

1. Ridley DS, Jopling WH. Classification of leprosy according to immunity. A five-group system. Int J Lepr Other Mycobact Dis. 1966;34(3):255-273.

2. Arnoldi J, Gerdes J, Flad HD. Immunohistologic assessment of cytokine production of infiltrating cells in various forms of leprosy. Am J Pathol. 1990;137(4):749-753.
3. Kempe S, Kestler H, Lasar A, Wirth T. NF-kappaB controls the global pro-inflammatory response in endothelial cells: evidence for the regulation of a pro-atherogenic program. Nucleic Acids Res. 2005;33(16): 5308-5319.

4. Denk A, Goebeler M, Schmid S, et al. Activation of NF-kappa B via the Ikappa B kinase complex is both essential and sufficient for proinflammatory gene expression in primary endothelial cells. $J$ Biol Chem. 2001;276(30):28451-28458.

5. Wang CY, Mayo MW, Korneluk RG, Goeddel DV, Baldwin AS Jr. NF-kappaB antiapoptosis: induction of TRAF1 and TRAF2 and c-IAP1 and c-IAP2 to suppress caspase-8 activation. Science. 1998;281(5383):1680-1683.

6. Elsharkawy AM, Oakley F, Mann DA. The role and regulation of hepatic stellate cell apoptosis in reversal of liver fibrosis. Apoptosis. 2005;10(5):927-939.

7. Oliveira RB, Ochoa MT, Sieling PA, et al. Expression of Toll-like receptor 2 on human Schwann cells: a mechanism of nerve damage in leprosy. Infect Immun. 2003;71(3):1427-1433.

8. Rambukkana A, Zanazzi G, Tapinos N, Salzer JL. Contact-dependent demyelination by Mycobacterium leprae in the absence of immune cells. Science. 2002;296(5569):927-931.

9. Hernandez Mde O, Fulco Tde O, Pinheiro RO, et al. Thalidomide modulates Mycobacterium leprae-induced NF- $\mathrm{KB}$ pathway and lower cytokine response. Eur J Pharmacol. 2011;670(1):272-279.

10. Sinsimer D, Fallows D, Peixoto B, Krahenbuhl J, Kaplan G, Manca C. Mycobacterium leprae actively modulates the cytokine response in naive human monocytes. Infect Immun. 2010;78(1):293-300.

11. Hernández-Presa MA, Gómez-Guerrero C, Egido J. In situ nonradioactive detection of nuclear factors in paraffin sections by Southwestern histochemistry. Kidney Int. 1999;55(1):209-214.

12. Gutierrez H, Hale VA, Dolcet X, Davies A. NF-kappaB signalling regulates the growth of neural processes in the developing PNS and CNS. Development. 2005;132(7):1713-1726.

13. Pinto AM, Sales PC, Camargos ER, Silva AM. Tumour necrosis factor (TNF)-mediated NF- $\mathrm{\kappa B}$ activation facilitates cellular invasion of nonprofessional phagocytic epithelial cell lines by Trypanosoma cruzi. Cell Microbiol. 2011;13(10):1518-1529.

14. Walsh DS, Lane JE, Abalos RM, Myint KS. TUNEL and limited immunophenotypic analyses of apoptosis in paucibacillary and multibacillary leprosy lesions. FEMS Immunol Med Microbiol. 2004;41(3):265-269.

15. Brito de Souza VN, Nogueira ME, Belone Ade F, Soares CT. Analysis of apoptosis and $\mathrm{Bcl}-2$ expression in polar forms of leprosy. FEMS Immunol Med Microbiol. 2010;60(3):270-274.
Journal of Inflammation Research

\section{Publish your work in this journal}

The Journal of Inflammation Research is an international, peer-reviewed open-access journal that welcomes laboratory and clinical findings on the molecular basis, cell biology and pharmacology of inflammation including original research, reviews, symposium reports, hypothesis formation and commentaries on: acute/chronic inflammation; mediators of inflamma-

\section{Dovepress}

tion; cellular processes; molecular mechanisms; pharmacology and novel anti-inflammatory drugs; clinical conditions involving inflammation. The manuscript management system is completely online and includes a very quick and fair peer-review system. Visit http://www.dovepress.com/ testimonials.php to read real quotes from published authors. 